\title{
Do It Yourself: Air Drag Force Experiment Using Paper and Scraper Sheet
}

\author{
Rizki Zakwandi ${ }^{1}$, Ariswan ${ }^{2}$, Syifa Nurfala ${ }^{3}$, Tiana Azmi Alawiyah ${ }^{4}$, Widya Amanda ${ }^{5}$, Ea \\ Cahya Septia Mahen ${ }^{6}$, Ade Yeti Nuryantini ${ }^{7}$ \\ Universitas Negeri Yogyakarta, Indonesia ${ }^{1,2}$, UIN Sunan Gunung Djati, Indonesia ${ }^{3,4,5,6,7}$ \\ rizkizakwandi.2020@ student.uny.ac.id ${ }^{1}$, ariswan@ uny.ac.id ${ }^{2}$, syifanurfalah81@ gmail.com ${ }^{3}$, \\ tiana.azmi@gmail.com ${ }^{4}$, widiyaamanda@gmail.com ${ }^{5}$, ea.cahya@uinsgd.ac.id ${ }^{6}$, \\ ade.yeti@uinsgd.ac.id ${ }^{7}$
}

Received: October $7^{\text {th }}, 2020$. Revised: December $27^{\text {th }}, 2020$. Accepted: January $12^{\text {th }}, 2021$

Keywords :

Drag Force; Physics

Experiment; Free Fall Motion;

Fluid Dynamic; Terminal

Velocity

\begin{abstract}
Free fall motion in air medium is only influenced by gravitation acceleration. However, there are several variables that caused the observations to be different with the concept. Variables, such as air drag and terminal velocity, are often teachers not presented in detail, causing misconceptions. This study aims to develop a simple experiment on free fall motion by identifying air drag and terminal velocity. The data in this study is the video of free fall motion of paper and scraper analyzed using Tracker video analyze. From the video analyzed, information is obtained in the form of time ( $t)$, track $(l, \theta)$, and velocity (v) of the object. This study shows that the air drag force increase unto the terminal velocity. The calculation of the drag coefficient giving the number of the paper 2,16 and the scraper 2,10. According to data analyzed, the air drag force is affected by the mass ( $m$ ), area (A), and the air drag force $\left(F_{D}\right)$ with the linear correlation until it reaches the terminal velocity. The result of this study may use as references of free fall motion experiment with other objects and analyze.
\end{abstract}

\section{INTRODUCTION}

Free fall motion is one of the motion phenomena with a vertical track. The difference between free fall motion and the others is the initial velocity. Newton's equation of free fall motion shows the phenomenon in ideal condition that is only affected by gravitational force [1]. Thus, in the real context, the motion of the object is affected by several variables such as height $\left(\mathbf{F}_{w}\right)$, the shape of objects, density $(\rho)$, area $(A)$, and the air condition which are pressure $(\mathrm{P})$, temperature $(\mathrm{T})$, moisture, and density as the medium of motion [2] [3]. However, these variables or quantity not provided in detail to students which causes misconceptions for students [4]. Students, in their observation, will state that in free fall motion it is affected by the mass of the object in which an object with a greater mass (i.e. rock and iron) will fall faster than a lighter object (i.e. a lump of cotton) [5] [6]. Misunderstanding phenomena occur because learning does not discuss and show factual phenomena how the airborne quantities work. 
The air is one of the kind the fluid and having the character of fluid as statics or dynamics. In the discussion of fluid mechanics, knowing that every motion in the fluid medium will resist by the drag force of fluid called fluid drag force and in this study is air drag forces. In the fluid system, the drag force depends on the flow of the fluid [7]. Drag force as one of the quantities affecting the phenomenon of free fall motion, it will be difficult if it is only explained theoretically. According to Ma'ruf et al [8], complex and abstract phenomena, such as drag force and terminal velocity, would be better explained by presenting a prototype to students. The prototype in the free fall motion experiment can also be interpreted as a comprehensive analysis of the free fall motion experiment.

The experiment of free fall motion usually focused on general magnitude. Such as of correlation of acceleration and mass, mass and track motion, or the correlation between the height and the acceleration and the track motion [9]. This study aims to make a design of a simple experiment of free fall motion to consider the factor in the tracking medium. Study by Firdaus et al [10] prove that learning using instructional media can correct misconceptions. Besides, Docktor and Mestre [6] also showed that another way to correct misconceptions is to present a phenomenon that is contrary with the concept adopted. The results of this study are expected to be able to assist teachers in conducting free fall motion experiments. Furthermore, with this simple experimental design, teachers can overcome misconceptions that occur in students, especially in the phenomenon of free fall motion.

\section{Newton's Mechanics}

The second of Newton's law explains that the force that works in the object motion is proportional to the change of momentum [11].

$$
\begin{gathered}
\mathbf{F}=\frac{d \mathbf{p}}{d t} \\
\mathbf{F}=m \cdot \mathbf{a}
\end{gathered}
$$

Considered the resistance factors such as air drag force and the Buoyancy's forces by means of Archimedes' law in motion, these correlation is expressed in Equation 3.

$$
-\mathbf{F}_{w}+\mathbf{F}_{u}+\mathbf{F}_{D}=-\mathbf{F}
$$

with $\mathbf{F}_{w}$ is the weight of the object. The negative sign at $\mathbf{F}_{w}$ and $\mathbf{F}$ show the direction of vector where gravitational acceleration worked to $\mathbf{F}_{w}$ and $\mathbf{F}$ have direction to the center of the earth, so the vector sign is negative. $\mathbf{F}_{u}$ represents the number of Bouyance's force and $\mathbf{F}_{D}$ is the air drag force with direction is opposite of the direction of object motion, like friction, so it is positive [12] Thus, the equation (3) may express as Equation 4.

$$
-m \cdot \mathbf{g}+V_{b} \cdot \rho \cdot \mathbf{g}+\mathbf{F}_{D}=-m \cdot \mathbf{a}
$$

with $m$ is the mass object $(\mathrm{kg}), V_{b}$ is the volume of the object $\left(\mathrm{m}^{3}\right)$ and $\rho$ is the density of the fluid (air) $\left(\mathrm{kg} / \mathrm{m}^{3}\right)$. In this case, the object that uses is a thin sheet by the paper and scraper, so the Buoyance's forces ignored because the number is too small.

\section{Air drag forces}

Air drag force have property like friction that resist the motion of an object. The air drag force is work in two directions that are direct force, the drag force that interact at the frontage of object, namely "pressure drag" and indirect force, the drag force that interact at the side of object, namely "shear drag" [13] [14] [15]. Equation 5 express the equation of the air drag force mathematically.

$$
\mathbf{F}_{D}=\frac{1}{2} \rho_{\text {air }} \cdot \mathbf{v}^{2} \cdot A \cdot C_{D}
$$


Do It Yourself: Air Drag Force Experiment Using Paper and Scraper Sheet Rizki Zakwandi, Ariswan, Syifa Nurfala, Tiana Azmi Alawiyah, Widya Amanda, Ea Cahya Septia Mahen,

Ade Yeti Nuryantini

$\mathbf{F}_{\mathrm{D}}$ has dimension as force with in unit Newton $(\mathrm{N}), \rho$ is the air density, in this case, the number of air density is $1.293 \mathrm{~kg} / \mathrm{m}^{3}, A$ is area $\left(\mathrm{m}^{2}\right)$ that parallels with direction of motion object $\mathbf{v}(\mathrm{m} / \mathrm{s})$ and $C_{D}$ is the drag coefficient depended on the shape of the object [16]. The drag force analyzed in this study is the pressure drag because the force is work like a pressure. To obtain the maximum pressure the area must be set parallel with the direction of motion. Whereas, the shear drag ignored because this force depends on the thickness of the object. In the simplicity of a term, the shear drag is work like a friction force and if the thin sheet object $(\mathbf{t} \approx 0)$ was used, this force can be ignored because the number is too small [17] [18] [19].

\section{Drag coefficient}

$C_{D}$ (coefficient drag) is magnitude that shows the levels of easily an object affected by the drag forces. The coefficient depends on the object, not the medium so these coefficient is effected by several factors such as shape, the motion situation, and the flow of medium [12] [17] [20]. The coefficient gives contribution in linear effect to the air drag force resulted. In the simple definition, the drag coefficient is a ratio of the drag force and the pressure of the object. Mathematically, it can be expressed in Equation 6 [15] [20].

$$
C_{D}=\frac{2 \mathbf{F}_{D}}{\rho \cdot \mathbf{v}^{2} \cdot A}
$$

Because there are two types of the drag force that are pressure drag and shear drag, Equation 7 and Equation 8 show the drag coefficient for each type. There are

$$
C_{D}=\frac{1.33}{\sqrt{\mathrm{Re}_{L}}}
$$

for pressure drag and

$$
C_{D}=\frac{0.0742}{\left(\operatorname{Re}_{L}\right)^{1 / 5}}
$$

for shear drag with $\operatorname{Re}_{L}$ is a function of Reynold's number that depends on the shape of an object.

\section{METHOD}

The research was begun by making an air-tight box in order to reduce external factors on track of objects (seen Figure 1). Then, the process was followed by making sample objects using paper and scraper cut as the thin sheet and square shape (seen Figure 2).

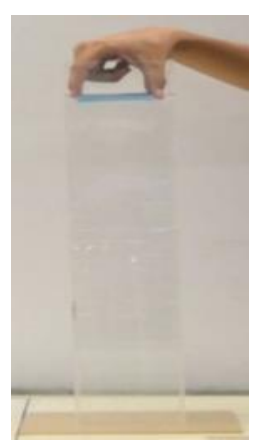


Fig 1. Box Track

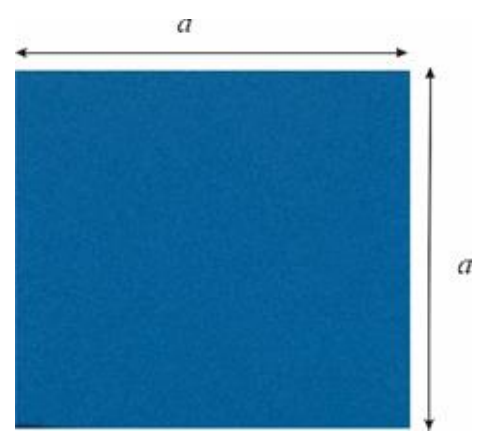

Fig 2. The sheet model of paper and scraper

To obtain data, there are three variables that was observed in this research. Each of them is area $(A)$, density $(\rho)$, and mass $(\mathrm{m})$ as the independent variable and the velocity $(\mathbf{v})$ as the dependent variable. Table 1 and Table 2 shows the variation of mass to be used while Table 3 and Table 4 show the variation of area of sheet. Variation of mass aimed to collect data analyzed for obtaining the information about effect of mass to air drag force. Besides, variation of area aimed to collect data analyzed for obtaining information about effect of area to air drag force. Both of variables, mass and area, were studied as a part of density which also contributed to air drag coefficient. The experiment was carried out in $28.4^{\circ} \mathrm{C}$ temperature and $73.9 \%$ moisture. Besides, another experiment that observed the contribution of area $(A)$ was carried on $26.4^{\circ} \mathrm{C}$ temperature and $69.6 \%$ moisture.

Table 1. The mass of paper sheet

\begin{tabular}{ccc}
\hline No & area $\left(\mathbf{c m}^{\mathbf{2}}\right)$ & mass $(\mathbf{g})$ \\
\hline 1 & 50.34 & 1.56 \\
2 & 50.34 & 1.85 \\
3 & 50.34 & 3.22 \\
4 & 50.34 & 4.06 \\
\hline
\end{tabular}

Table 2. The mass of scraper sheet

\begin{tabular}{ccc}
\hline No & area $\left(\mathbf{c m}^{\mathbf{2}}\right)$ & mass $(\mathbf{g})$ \\
\hline 1 & 35.88 & 0.70 \\
2 & 35.43 & 1.10 \\
3 & 36.24 & 1.20 \\
4 & 36.99 & 1.70 \\
5 & 36.72 & 1.80 \\
\hline
\end{tabular}

Table 3. The area of the paper sheet

\begin{tabular}{ccc}
\hline No & area $\left(\mathbf{c m}^{\mathbf{2}}\right)$ & mass $(\mathbf{g})$ \\
\hline 1 & 49.81 & 1.20 \\
2 & 42.77 & 1.20 \\
3 & 36.15 & 1.20 \\
4 & 30.53 & 1.20 \\
5 & 25.40 & 1.20 \\
\hline
\end{tabular}

Table 4. The area of scraper sheet

\begin{tabular}{ccc}
\hline No & area $\left(\mathbf{c m}^{\mathbf{2}}\right)$ & mass $(\mathbf{g})$ \\
\hline 1 & 49.63 & 1.20 \\
2 & 42.12 & 1.20 \\
3 & 35.79 & 1.20 \\
4 & 30.91 & 1.20 \\
5 & 25.14 & 1.20 \\
\hline
\end{tabular}


Do It Yourself: Air Drag Force Experiment Using Paper and Scraper Sheet Rizki Zakwandi, Ariswan, Syifa Nurfala, Tiana Azmi Alawiyah, Widya Amanda, Ea Cahya Septia Mahen,

Ade Yeti Nuryantini

The data was collected by using 13 Mega-Pixel of camera resolution and 30 frames per second (fps) recorder. The video contained records of moving objects in the air-tight box which was fallen without initial velocity. Then, these video was analyzed including imaging position of each time, velocity, and acceleration of the object by using Tracker video analyses.

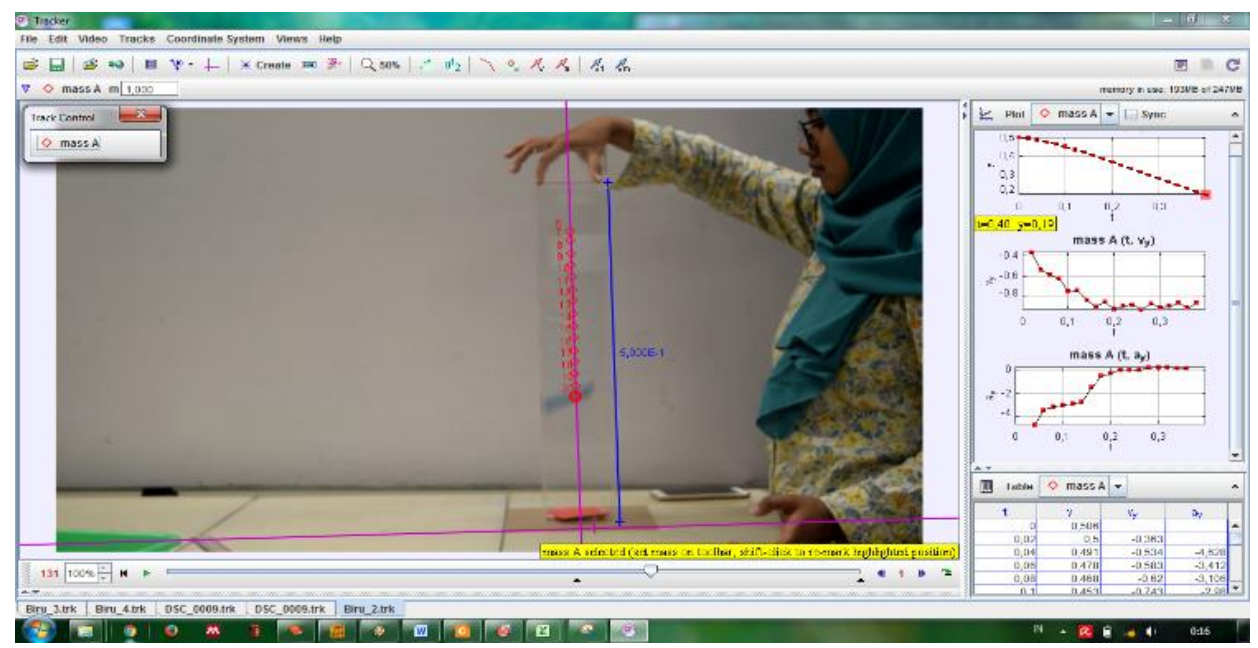

Fig 3. The Tracker video analyses.

\section{RESULTS AND DISCUSSIONS}

The result of the experiment by falling object from $50 \mathrm{~cm}$ provides the inversely proportional correlation between mass $(\mathrm{m})$ and air drag forces $\left(\mathbf{F}_{D}\right)$, while the area $(A)$ provides proportional correlation toward air drag forces $\left(\mathbf{F}_{D}\right)$.

Table 5. The velocity and acceleration of the scraper sheet in constant area.

\begin{tabular}{|c|c|c|c|}
\hline No & Mass (kg) & $\mathrm{v}(\mathrm{m} / \mathbf{s})$ & $a\left(\mathrm{~m} / \mathrm{s}^{2}\right)$ \\
\hline 1 & 0.0007 & 0.92 & 0.74 \\
\hline 2 & 0.0011 & 1.06 & 2.07 \\
\hline 3 & 0.0017 & 1.05 & 2.96 \\
\hline 4 & 0.0018 & 1.29 & 4.07 \\
\hline
\end{tabular}

Table 6. The velocuty and acceleration of scraper sheet in constant mass.

\begin{tabular}{cccc}
\hline No & Area $\left(\mathbf{m}^{2}\right)$ & $\mathbf{v}(\mathbf{m} / \mathbf{s})$ & $\mathbf{a}\left(\mathbf{m} / \mathbf{s}^{2}\right)$ \\
\hline 1 & 0.004963 & 0.85 & 1.10 \\
2 & 0.004212 & 0.98 & 1.61 \\
3 & 0.003579 & 1.16 & 2.80 \\
4 & 0.003091 & 1.23 & 3.38 \\
5 & 0.002514 & 1.45 & 3.57 \\
\hline
\end{tabular}

Table 5 shows that velocity (v) and acceleration (a) increases proportional to the increase of mass. By using the second of Newton's law in motion that indicate of constant of gravitation acceleration, the change of the acceleration object was caused by the air drag forces $\left(\mathbf{F}_{D}\right)$. According to equation 2, air drag forces can be expressed as mass object times to delta acceleration. Generally, the increasing of the velocity (v) and acceleration (a) indicate that there is maximum of air drag force $\left(\mathbf{F}_{D}\right)$ in the system. If the correlation of mass and density in same volume, the higher mass of object the higher level of density. Thus, it also shows that air drag force is increases proportionally to the density. 
According to Table 6, acceleration increases proportionally to the decrease of area. Thus, the wider the area, the greater the air drag force. This is logic, because the area, in this case is surface, has interaction to the air particle. Thus, the wider area the more interaction happen that cause the higher air drag force received by the objects. Furthermore, see Figure 4 and Figure 5 which show the direction of the object.

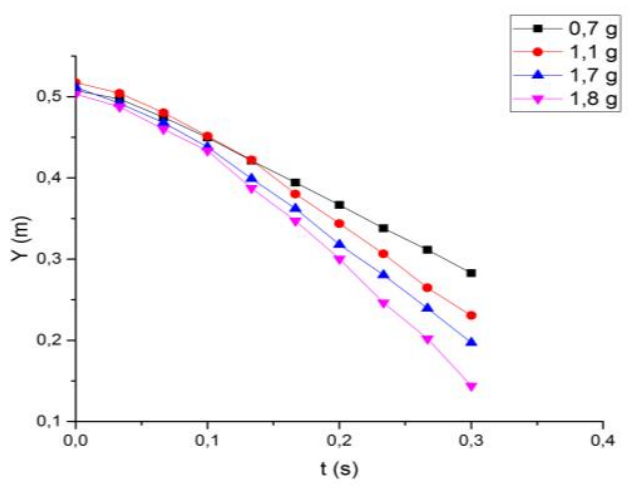

Fig 4. Correlation of $Y(m)-t(s)$ of scraper sheet in the constant area.

Figure 4 shows the correlation of height ( $\mathrm{Y}$-axis) and the time $(\mathrm{t})$ of scraper sheet motion in free fall motion track. According to Figure 4, the gradient increases with proportional to the increase of mass that indicates by increasing the mass of the object can be increasing the air drag forces.

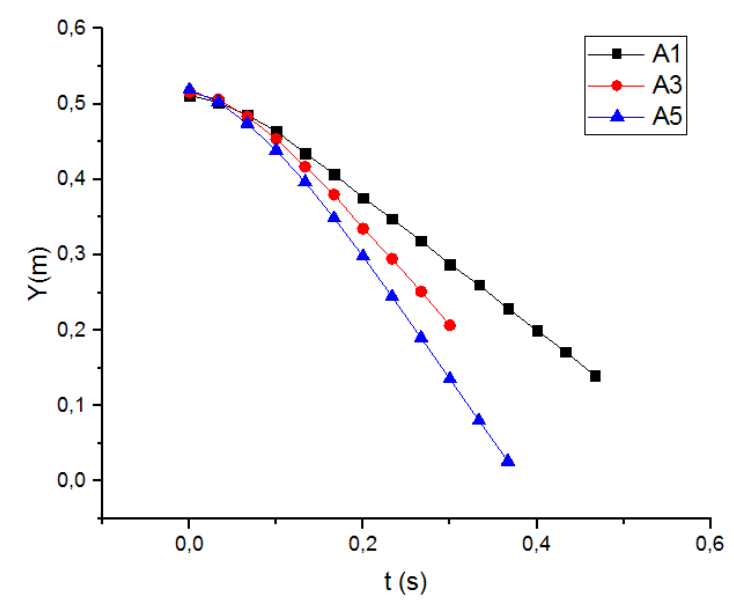

Fig 5. The correlation of $Y(m)-t(s)$ in the constant mass.

Figure 5 is the direction of several scrapers which have different sizes of area in which the sizes of scrapers are $A 1>A 3>A 5$. The data in Figure 5 shows that the slope angle of the graph increases as the decreases of object's size. That is, the gradient of the graph is inversely proportional with the area size. The area has interaction with the air drag forces. The wider area, the more air drag forces received. These finding prove the equation of $\mathbf{F}_{\mathrm{D}}$ shown the value of $\mathbf{F}_{\mathrm{D}}$ proportional to area $(A)$. Next, Eq. 3 shows that $\mathbf{F}_{\mathrm{D}}$ has the negative sign, so in free fall motion area work as a resistance to motion [16] [21]

Figure 4 and Figure 5 indicates that the direction of free fall motion is parabolic. This condition complies with the general equation of motion (seen Equation 9) with acceleration [22].

$$
h(y)=h_{o}+v_{o} t-1 / 2 g t^{2}
$$


Do It Yourself: Air Drag Force Experiment Using Paper and Scraper Sheet Rizki Zakwandi, Ariswan, Syifa Nurfala, Tiana Azmi Alawiyah, Widya Amanda, Ea Cahya Septia Mahen, Ade Yeti Nuryantini

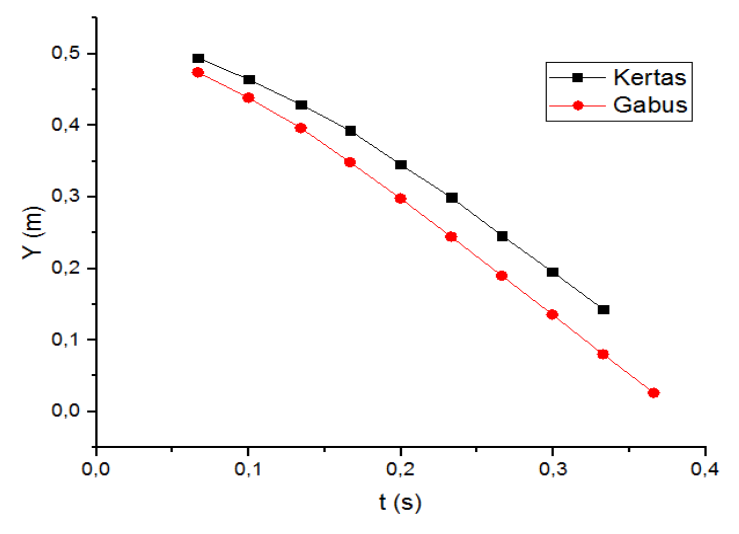

Fig 6. The comparison of paper and scraper sheet track motion.

The comparison of a height of paper and scraper sheet in Figure 6 showed that both objects, paper and scraper, has same gradient which indicates velocity is relatively alike. However, there are difference od height object in every time where paper sheet has higher coordinate than those of scraper sheets. This is caused by the density of the object. Analytically, the paper sheet has higher density than scraper sheet does. According to these finding, it can be concluded that the density gave a numerical effect to the air drag forces. The explanation of this phenomenon is when an object which low density is held by the air drag forces; the working force does not completely hold the object because some air particles can pass through the space between the particles of the object. This analogy is similar to another fluid flow, water. In other site, low density will increase the shear drag force and it one of much reason that caused the difference of the air drag force working on between paper and scraper [17] [23].

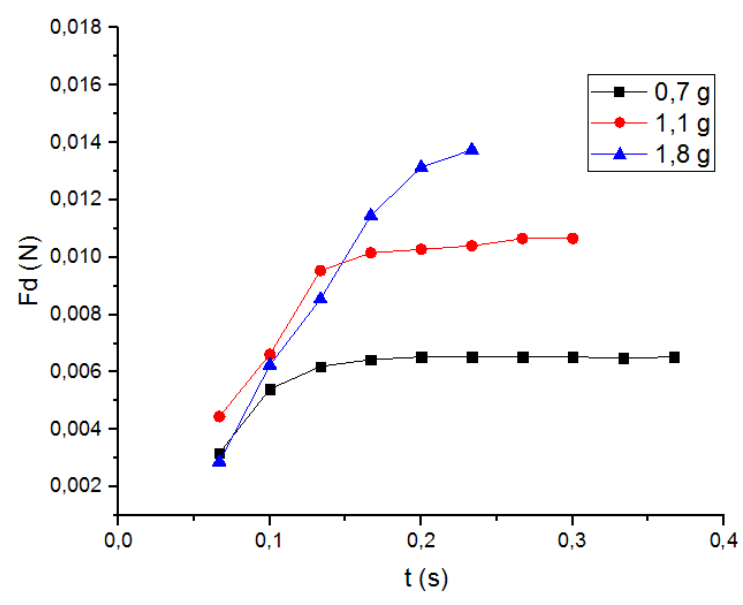

Fig 7. The correlation of $F d(N)-t(s)$ of the scraper in the constant area.

Figure 7 shows that the line have the constant value at the end. Generally, air drag forces increase before the terminal velocity. According to Equation 5, it is happened in simple correlation that if the air drag forces have constant value, the acceleration must be zero and indicates that the object was in terminal velocity. Terminal velocity occurs when air drag forces has the same value as weigh. According to findings, air drag forces have the opposite direction with the acceleration, so the air drag force has the other correlation with mass in which air drag forces are inversely proportional to mass. The higher mass objects, the smaller air drag caused and the higher velocity of objects. This finding was also confirm with the terminal velocity rule in free fall motion [20] [24]. 
JIPF, Vol. 6 No. 3, September 2021

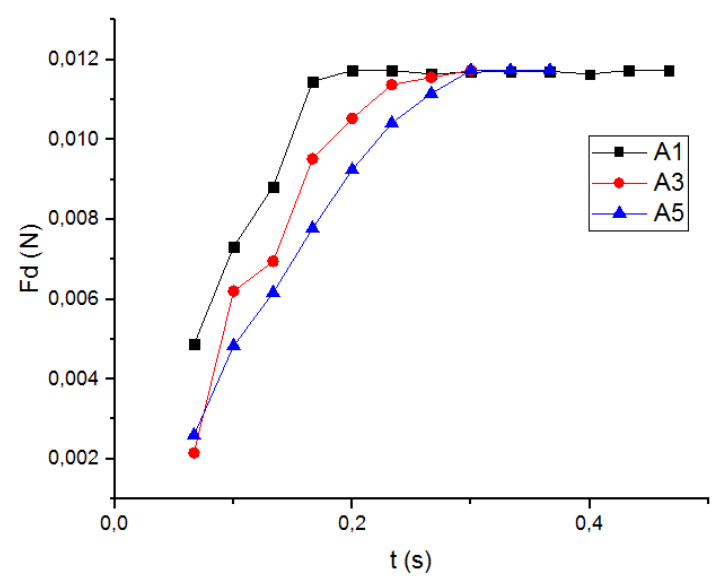

Fig 8. Correlation of $F d(N)-t(s)$ in the scraper at the constant mass.

Figure 8 shows the correlation between area and air drag forces where air drag forces has is same for all of sizes sheets when it was in terminal velocity. Thus, it can be concluded that air drag force does not depend on the area where it was in terminal velocity, and the terminal velocity is not depending on the size of objects. Because of $A 1>A 2>A 3$, Figure 8 indicates that the size of area only has an effect before the objects extend the terminal velocity. Furthermore, the correlation of area and air drag forces is linear and the size of area only affects the time to reach terminal velocity [25] [26]. The larger of the object area is, the faster the object reaches terminal velocity.

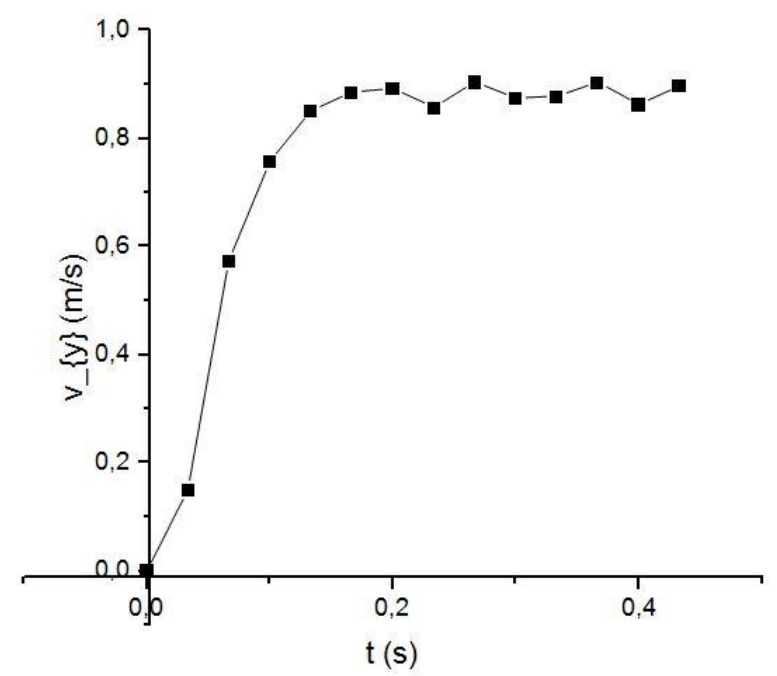

Fig 9. Terminal Velocity

Figure 9 shows the changes in velocity as acceleration decreases shown by the gradient that initially shows an acceleration (before $\mathrm{t}=0.2$ there is gradient) until the graph is flat. It can be concluded that there is a uniform linear motion which indicates the terminal velocity [27] [28]. Assuming that the value of gravity is equal to the value of the air drag, the value of the air drag coefficient can be determined. The calculation of drag coefficient gives the value of drag coefficient $\left(\mathrm{C}_{D}\right)$ of scraper sheet 2.10 and 2.16 to the paper sheet. The drag coefficient refers to air drag force in terminal velocity by the object [17] [22] [29]. Based on the results, the experiments design gives results close to literature. So it can be applied in school. It can be used as large scale testing of the experiment that developed. 
Do It Yourself: Air Drag Force Experiment Using Paper and Scraper Sheet Rizki Zakwandi, Ariswan, Syifa Nurfala, Tiana Azmi Alawiyah, Widya Amanda, Ea Cahya Septia Mahen, Ade Yeti Nuryantini

\section{CONCLUSION AND SUGGESTION}

The experimental design of free fall motion using paper and scraper can be used to define air drag forces. The use of Tracker video analyses in the same project gives a convenience to analyze object motion. The number of air drag forces is effect by several factors; that are 1) mass, with proportional correlation toward the air drag forces, 2) area, with proportional correlation, 3) density, with proportional correlation. Mass determine the weight of the object that cause the change of velocity. The area made the time of objects to reach terminal velocity different. Especially, the area is only given effect before terminal velocity reach. The calculation of drag coefficient gives the value of drag coefficient $\left(\mathrm{C}_{D}\right)$ of scraper sheet 2.10 and 2.16 to the paper sheet.

\section{ACKNOWLEDGMENTS}

Authors would like to show our gratitude to Ministry of Finance of the Republic of Indonesia, this work was supported in part by a grant from Indonesia Endowment Fund for Education (LPDP).

\section{REFERENCES}

[1] Jewett, J. W., \& Serway, R. A. (2008). Physics for scientists and engineers with modern physics. Cengage Learning EMEA.

[2] Liu, X., Lin, P., \& Shao, S. (2014). An ISPH simulation of coupled structure interaction with free surface flows. Journal of Fluids and Structures, 48: 46-61.

[3] Falcovich, G.. \& Weizmann. (2011). Fluid Mechanics (A Short course for physicist). Cambridge: Cambridge University Press.

[4] Jugueta, E. A. D., Go, C. K. C., \& Indias, J. M. M. (2012). Free fall misconceptions: A comparison between science and non-science university majors. Lat. Am. J. Phys. Educ, 6(S1): 2-5.

[5] Sulistri, E., \& Lisdawati, L. (2017). Using Three-Tier Test to Identify the Quantity of Student that Having Misconception on Newton's Laws of Motion Concept. JIPF (Jurnal Ilmu Pendidikan Fisika), 2(1): 4-6.

[6] Docktor, J. L., \& Mestre, J. P. (2014). Synthesis of discipline-based education research in physics. Physical Review Special Topics-Physics Education Research, 10(2): 020119.

[7] Dasriyani, Y., Hufri, \& Yohandri. (2015). Pembuatan Set Eksperimen Gerak Jatuh Bebas Berbasis Mikrokontroler dengan Tampilan PC. Pillar of Physics, 5(1): 89-96.

[8] Ma'ruf, F., Septiansyah, F. A., \& Wibowo, H. A. C. (2019). Rancangan Prototype Kereta Maglev Sebagai Media Pembelajaran Kontekstual Untuk Menjelaskan Materi Fisika Elektromagnetika. FKIP e-PROCEEDING, 4(1): 87-91.

[9] Wee, L. K., Tan, K. K., Leong, T. K., \& Tan, C. (2015). Using Tracker to understand 'toss up'and free fall motion: a case study. Physics Education, 50(4): 436-442.

[10] Firdaus, T., Erwin, E., \& Rosmiati, R. (2019, February). Learning media free fall motion to reduce misconceptions and improve students' understanding of the concept. In Journal of Physics: Conference Series (Vol. 1157, No. 3, p. 032072). IOP Publishing.

[11] Fowles, G. R., \& Cassiday, G. L. (2005). Analytical mechanics. Belmont, CA: Thomson Brooks/Cole,.

[12] Barrio-Perotti, R., Blanco-Marigorta, E., Argüelles-Díaz, K., \& Fernández-Oro, J. (2009). Experimental evaluation of the drag coefficient of water rockets by a simple free-fall test. European journal of physics, 30(5): 1039-1048.

[13] Löfdahl, L., \& Gad-el-Hak, M. (1999). MEMS-based pressure and shear stress sensors for turbulent flows. Measurement Science and Technology, 10(8): 665-686.

[14] Forjan, M., \& Sliško, J. (2017). Simplifications and idealizations in high school physics in Mechanics: a study of Slovenian curriculum and textbooks. European Journal of Physics Education, 5(3): 20-31. 
[15] Tinney, C. E., \& Valdez, J. (2018). A new test stand for measuring wall shear stress. In 2018 Fluid Dynamics Conference (p. 3085).

[16] Maroto, J. A., Duenas-Molina, J., \& de Dios, J. (2005). Experimental evaluation of the drag coefficient for smooth spheres by free fall experiments in old mines. European journal of physics, 26(3): 323-330.

[17] Landell-Mills, N. (2017). Buoyancy Explains Terminal Velocity in Skydiving. Journal of Aeronautics \& Aerospace Engineering, 6(2): 1-7.

[18] Susanti, S., Mahen, E. C. S., \& Nuryantini, A. Y. (2018). Preliminary study of software tracker usage to analyze inhibitory style on free fall movie events. In MATEC Web of Conferences (Vol. 197, p. 02012). EDP Sciences.

[19] Jung, T., Choi, H., \& Kim, J. (2016). Effects of the air layer of an idealized superhydrophobic surface on the slip length and skin-friction drag. Journal of Fluid Mechanics, 790.

[20] Pritchard, P. J., \& Mitchell, J. W. (2016). Fox and McDonald's introduction to fluid mechanics. John Wiley \& Sons.

[21] Pande, J., \& Smith, A. S. (2015). Forces and shapes as determinants of micro-swimming: effect on synchronisation and the utilisation of drag. Soft Matter, 11(12): 2364-2371.

[22] Tang, S., \& Kumar, V. (2015, May). Mixed integer quadratic program trajectory generation for a quadrotor with a cable-suspended payload. In 2015 IEEE International Conference on Robotics and Automation (ICRA) (pp. 2216-2222). IEEE.

[23] Maeda, T., Kamada, Y., Murata, J., Shimizu, K., Ogasawara, T., Nakai, A., \& Kasuya, T. (2016). Effect of solidity on aerodynamic forces around straight-bladed vertical axis wind turbine by wind tunnel experiments (depending on number of blades). Renewable energy, 96: 928-939.

[24] Pourtousi, M., Sahu, J. N., \& Ganesan, P. (2014). Effect of interfacial forces and turbulence models on predicting flow pattern inside the bubble column. Chemical Engineering and Processing: Process Intensification, 75: 38-47.

[25] Pande, J., \& Smith, A. S. (2015). Forces and shapes as determinants of micro-swimming: effect on synchronisation and the utilisation of drag. Soft Matter, 11(12): 2364-2371.

[26] Liu, L., Yan, H., Zhao, G., \& Zhuang, J. (2016). Experimental studies on the terminal velocity of air bubbles in water and glycerol aqueous solution. Experimental Thermal and Fluid Science, 78: 254-265.

[27] Dioguardi, F., Mele, D., Dellino, P., \& Dürig, T. (2017). The terminal velocity of volcanic particles with shape obtained from 3D X-ray microtomography. Journal of Volcanology and Geothermal Research, 329: 41-53.

[28] McGaugh, S. S. (2015). The surface density profile of the galactic disk from the terminal velocity curve. The Astrophysical Journal, 816(1): 42.

[29] Xu, B., Huang, N., He, W., \& Chen, Y. (2017, April). Investigation on terminal velocity and drag coefficient of particles with different shapes. In Journal of Physics: Conf. Series (Vol. 822, p. 12047). 